Review Article

\title{
Advances in Structural Control in Civil Engineering in China
}

\section{Hongnan Li and Linsheng Huo}

State Key Laboratory of Coastal and Offshore Engineering, Dalian University of Technology, Dalian 116024, China

Correspondence should be addressed to Hongnan Li, hnli@dlut.edu.cn

Received 30 July 2009; Accepted 25 November 2009

Academic Editor: José Balthazar

Copyright (C) 2010 H. Li and L. Huo. This is an open access article distributed under the Creative Commons Attribution License, which permits unrestricted use, distribution, and reproduction in any medium, provided the original work is properly cited.

In the recent years, much attention has been paid to the research and development of structural control techniques with particular emphasis on alleviation of wind and seismic responses of buildings and bridges in China. Structural control in civil engineering has been developed from the concept into a workable technology and applied into practical engineering structures. The aim of this paper is to review a state of the art of researches and applications of structural control in civil engineering in China. It includes the passive control, active control, hybrid controland semiactive control. Finally, the possible future directions of structural control in civil engineering in China are presented.

\section{Introduction}

Civil engineering structures located in environments where earthquakes or large wind forces are common will be subjected to serious vibrations during their lifetime. These vibrations can range from harmless to severe with the later resulting in serious structural damage and potential structural failure. The traditional method of antiseismic technique is to increase the stiffness of structures by enlarging the section of columns, beams, shear walls, or other elements, which will enhance the seismic load because of the added mass to structures. As a result, although the cost of structures with traditional antiseismic technique is increased a lot, the safety level of structures is less improved. Another disadvantage of the traditional antiseismic technique is that it focuses on the protection of the structure but neglects the facilities inside the structure. Hence, it cannot be used in some structures whose facilities inside them are very important, such as hospitals, city lifeline engineering, nuclear plants, museum buildings, and the buildings with precise instruments. 
Even though engineers cannot design a building which is damage-proof during earthquakes and strong winds, the structural control is promising in reducing the vibration of structures. Different from the traditional antiseismic method, the structural control technique suppresses the structural vibration by installing some devices, mechanisms, substructures in the structure to change or adjust the dynamic performance of the structure. The structural control system is commonly classified by its device type resulting in four general control types: passive, active, hybrid, and semi-active control. An active control system is the one in which an external source power control actuators apply forces to the structure in a prescribed manner including active tendon system (ATS) and active mass damper (AMD). A passive control system does not require an external power source, such as base isolation method, energy dissipation devices, tuned mass damper (TMD), and tuned liquid damper (TLD). The hybrid control implies the combined use of active and passive control systems. Semiactive control systems are a class of active systems in which only small magnitude of external energy is needed to change the parameters of control system, such as active variable stiffness (AVS) system and active variable damper (AVD) system.

In the recent years, serious efforts have been undertaken in structural control and fruitful achievements have been made in China. Structural control has been developed from theoretical analysis and experimental research into engineering applications. A set of techniques including base isolation, energy dissipation, tuned mass dampers, tuned liquid dampers, active and semi-active control methods have been used in newlybuilt structures or existing buildings, bridges, facilities, and other structures in China. In this paper, the state of art of vibration control techniques, including theoretical and experimental studies, practices in civil engineering are reviewed. The possible future directions of structural control in civil engineering is discussed.

\section{Passive Control}

\subsection{Base Isolation}

The base isolation system was developed as one of remarkable technologies to reduce the seismic load of building and equipment. There are five kinds of materials that have been used for isolators in China, including sand layer, graphite lime mortar layer, slide friction layer, roller and rubber bearing. The rubber bearing is the one used mostly in China. Relatively easy to be manufactured, isolation bearings are made by vulcanization bonding of sheets of the rubber to thin steel reinforcing plates. The bearings are very stiff in the vertical direction, while quite flexible in the horizontal direction. Under the excitation of horizontal earthquakes, the fundamental vibration period of an isolated structure can be shifted from a short-period range to a long-period range. Thus, the horizontal seismic response of the isolated structure is significantly less than the unisolated structure. The significant advantages of structures with rubber bearing isolators are summarized as follows [1].

(1) The isolated structures are safer in strong earthquake. The isolators are very effective to reduce the seismic response of structures and can prevent the structures from damage or collapse. Compared to the traditional antiseismic structures, the responses of isolated structures can be reduced to $1 / 2 \sim 1 / 8$ of the one of traditional structures, according to the testing results and the records in real earthquake. 


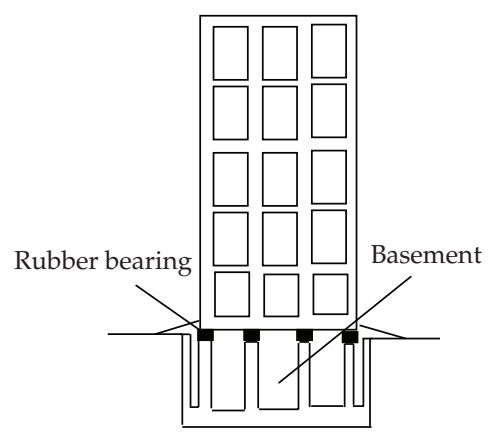

(a)

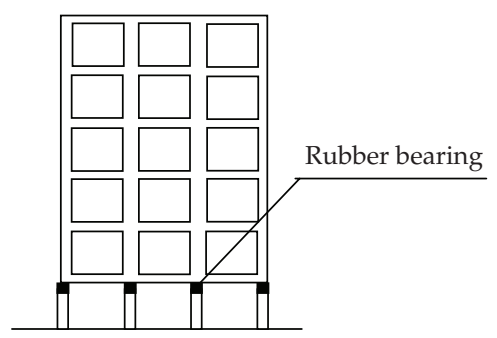

(b)

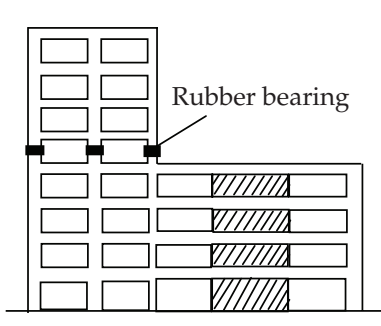

(c)

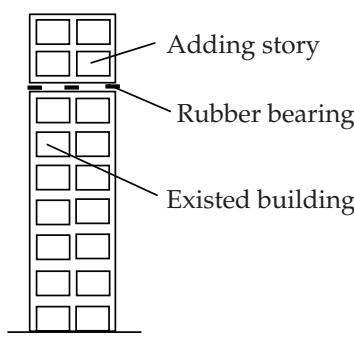

(d)

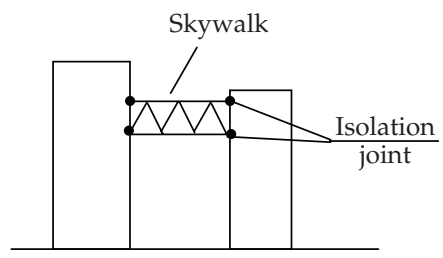

(e)

Figure 1: Different locations of Isolation Layer in Structure. (a) Basement isolation; (b) Story isolation with isolators on the top of the first story; (c) Story isolation with isolators on certain story of supper structures; (d) Top isolation; (e) Skywalk linking isolation.

(2) The building cost of isolation structures can be saved 3\% 15\% of the cost of the general buildings according to the final statistics results of 30 buildings with rubber bearings completed in southern, western, and northern China.

(3) The seismic isolation rubber bearing system has wide ranges of application, both in newly designed structures and existing structures, important buildings and civil buildings especially for house buildings, for protecting the building structures, and for protecting the facilities inside the building.

(4) The safely working life of rubber bearings is over 70-100 years according to the permanent testing and investigation, which is larger than the working life of structure itself.

In order to solve some problems for more wide application of isolation systems, a great number of tests for rubber bearings and shaking table tests for building models were carried out by Zhou and Xian [2]. The test of mechanical characteristics for isolators includes the compression tests, compression with shear cycle loading tests. The test of durability for isolators includes low cycle fatigue tests, creep tests, and ozone aging tests. The test of structural system includes shaking table tests for large-scale structural model.

There are five kinds of locations of layer with rubber bearings in China [3]. Isolation layer is located on the base of building, which is the most common method. The isolation layer can be located on the certain story of the basement, which is used in many structures as shown in Figure 1(a). The isolation can also be located on the top of the first story (Figure 1(b)) or certain story of superstructure (Figure 1(c)). The isolation layer located 
on the top of the building (Figure 1(d)) is always used to add 1-2 stories on the top of existed building for seismic retrofit. Isolation layer located at the joints between skywalk and buildings (Figure 1(e)) is used to separate the different mode shapes of buildings connected by skywalk.

In the case of a seismic isolated building with a large height-to-width ratio (HWR), the overturning moment at the level of seismic isolated layer may exceed the overturning resistance supplied by the gravity, which will result in the disconnection of bearings from the superstructure and produce an internal damages of rubber layers, even lead to a destroy of the entire building. The limits of the HWR for isolated building with the laminated rubber bearings under different conditions subjected to earthquake excitations were investigated by $\mathrm{Li}$ and $\mathrm{Wu}$ [4]. According to the numerical results, it has been found that the effects of site soil conditions on the HWR limit values are very important, in which the softer the site is, the smaller the HWR limit value is under different seismic intensities. The predominant period of isolated building also plays a considerable role in the HWR limit value namely, the isolated building with a longer period may have a relatively large HWR value. The stiffness of superstructure has little effects on the HWR limit value.

Most structures are simplified as planar models in base isolation design. However, a lot of structures are eccentric due to plan irregularity, mass eccentricity, elevation irregularity, and so forth The earthquake is essentially multidimensional and so is the structural response excited by earthquake, which will result in the torsionally coupled vibration that cannot be neglected. Based on many numerical analyses on different soil sites during the action of earthquakes, simplified formulate of torsional seismic actions for base-isolated eccentric structures is presented [5]. It is shown that the proposed formulations have good accuracy compared with others. It provides a convenient and simplified method for the structural design of base-isolated eccentric buildings with rubber pads.

Design principles of base isolation and energy dissipation systems are also included in Chinese Code for Seismic Design of Buildings published by the agency of Ministry of Construction in 2001. The design codes for base isolated highway bridges and base isolated railway bridges were also published by the agencies of Ministry of Transportation and Ministry of Railway. Currently, there are three different sets of technical codes on seismic isolation in China [3].

(1) Technical Specification for Seismic Isolation with Laminated Rubber Bearing Isolators (CECS 126: 2001). This is the national code for design and construction of buildings and bridges with seismic isolation in China.

(2) Standard of Laminated Rubber Isolators (JB 118-2000). This is the national standard of isolators for laminated rubber bearing in China.

(3) Seismic Isolation and Energy Dissipation for Building Design (Chapter 12 in the code for seismic design of buildings, GB 50011-2001). This is a part of national code in China for seismic design of buildings.

Some main introductions for all these three codes (standards) on seismic isolation in China are described as below [3].

(1) Provide the design methods of seismic isolation for buildings, bridges, special structures, and industry facilities.

(2) Provide the design methods of seismic isolation for new structures and the retrofit of existed structures. 
(3) Allow to follow three design levels depending on the importance of structures and requirements of owners in the areas with different economic situation in China. Level 1, for general structures, using isolation will save building cost about $3 \% \sim 15 \%$. Level 2, for important structures, using isolation will increase building cost 3\% 5\%. Level 3, for especially important structures, using isolation will increase building cost $5 \% \sim 7 \%$. But the isolation buildings designed by any level will increase the seismic safety about $2 \sim 8$ times compared with the traditional antiseismic buildings.

(4) Provide two methods of structural analysis for seismic isolation of structures, equivalent shear method, and time-history analysis. The equivalent shear method is achieved by static analysis and only applicable for structures with height less than $40 \mathrm{~m}$ or 10 stories, regular configuration, and predominant shear deformations. Whereas, the time-history analysis can be used for all kinds of structures.

(5) Allow reducing the seismic shear force for designing superstructure, which can save the building cost of general civil buildings, especially in some poor economic areas.

(6) Control the maximum horizontal shear displacement $D_{\max }$ of isolation layer. The value of $D_{\max }$ will not be larger than 0.55 times of diameter of bearing and $300 \%$ shear strain deformation of bearings. $D_{\max }$ should be the total displacement including both translation and torsion of structural system.

The first multistory house building with rubber bearing in China was completed in 1993, as shown in Figure 2 [3]. It is an 8-story building supported by 23 rubber bearings with different diameters from $60 \mathrm{~cm}$ to $80 \mathrm{~cm}$. The structure has undergone two strong earthquakes in 1994 and 1996 and is still employed now without any damage. The isolated buildings with the largest area in the world are named Isolation House Buildings on Subway Hub (IHBSH) as shown in Figure 3, which is located nearly the center of Beijing [3]. There is a very large platform composed by an RC frame with two sorties, which is used to put all equipment and facilities for railway hub in it and cover the noise from railway hub trains. The size of platform is $1500 \mathrm{~m}$ wide and $2000 \mathrm{~m}$ long. There are 50 house buildings built on the top floor of the platform. The floor area of all isolation house buildings is approximately $480000 \mathrm{~m}^{2}$ which is the largest area using seismic isolation in the world. The rubber bearing layer is located on the top floor of the platform, as shown in Figure 4. The great benefits are achieved by using story isolation for this building complex including: increasing the safety of structures to 4 times of traditional design schemes, saving $25 \%$ of the construction cost, raising the number of stories from 6 to 9 , and solving the environmental problems of railway vibration and noise in the city center.

The application of seismic isolators in China has proved that the isolation system is more safe, economic, and reasonable than the traditional structural system. More than 500 full-scale implementations of base isolated buildings and bridges have been accomplished to alleviate the earthquake and traffic induced response so far [6].

\subsection{Energy Dissipation}

An energy dissipation system is formed by adding some energy dissipaters into the structure. The energy dissipaters provide the structure with large amounts of damping which will dissipate most vibration energy from vibration sources and ensure the safety of structures in 


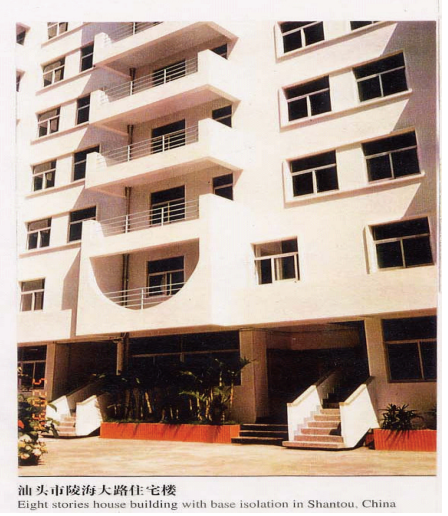

(a) Outside view

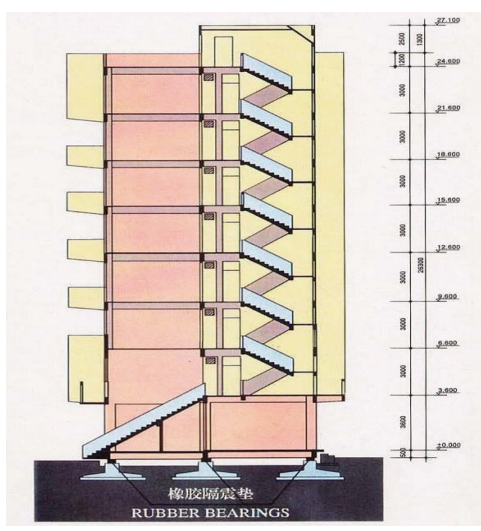

(b) Sectional view

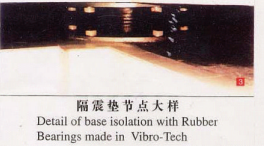

(c) Details of rubber bearing

Figure 2: The first multistory house building with rubber bearing in China.

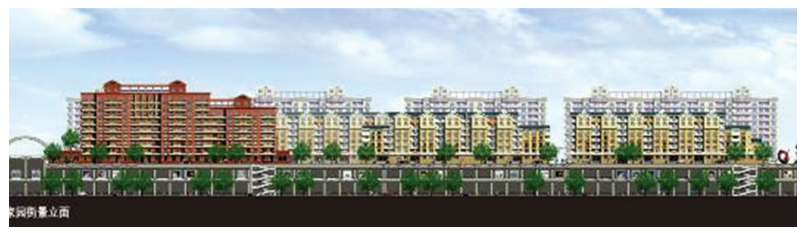

Figure 3: Front elevation of IHBSH.

earthquake or the comfort level in wind. Many kinds of dampers, including friction dampers, viscoelastic dampers, viscous fluid dampers, lead dampers and metallic dampers have been developed in China.

Friction provides an excellent mechanism of energy dissipation and has been used for many years in automotive brakes to dissipate kinetic energy of motion. This kind of dampers are made of ordinary materials with simple mechanical configurations; hence they are applicable for multi-story and high-rise buildings. The behaviors of two different energy dissipation dampers based on friction as shown in Figure 5 were studied by Zhou and Liu [7]. The results showed that the friction energy dissipation dampers can dissipate a great deal of earthquake input energy and the hysteretic behavior is stable. To satisfy the energy dissipation requirements for earthquake in different seismic intensities of China, doublephase friction dampers were proposed by Zhang and Yang [8]. The experimental results showed that the proposed double phase friction damper can reduce the structural vibrations both in small and strong earthquake. Wu and $\mathrm{Ou}$ [9] presented a kind of pseudofriction damper to reduce the effects of additional stiffness in Pall friction dampers. Based on the geometry nonlinearity of four-link mechanism of Pall-typed friction damper, the influence of frame displacement, brace stiffness, damper slip force of a novel pseudoviscous frictional damper as shown in Figure 6, is analyzed by Wu et al. [10]. The results showed that the novel frictional damper has great hysteretic characteristics with remarkably smaller tension force of brace than that of pall-typed friction damper, which is beneficial for frame columns to improve its ductility. A damper with innovative composite friction material has been developed by Xian et al. [11]. A full-scale test of this innovative friction damper and the 


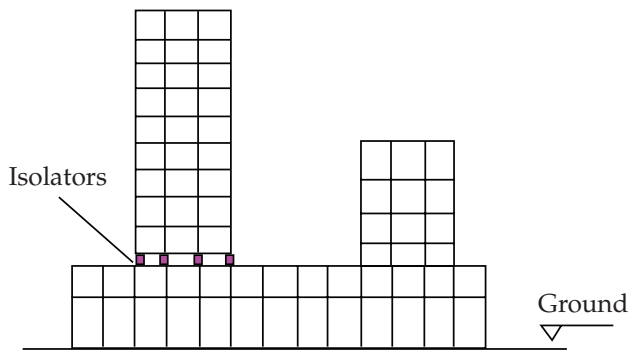

Figure 4: Stories Isolation used in IHBSH.

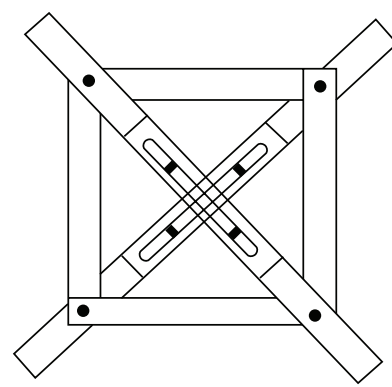

(a) Type A

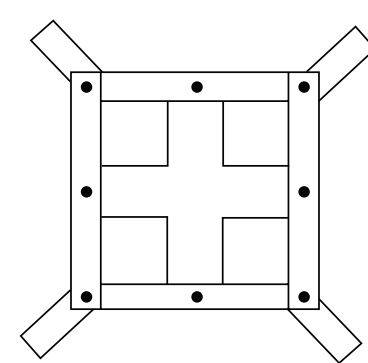

(b) Type B

Figure 5: Two types of friction dampers.

shaking table test for structural model with the damper were implemented, which showed that the seismic responses of structures with dampers can be reduced $30 \% \sim 40 \%$. The friction dampers have been applied in engineering structures in China. For example, 134 passive friction dampers with $100 \mathrm{kN}$ to $200 \mathrm{kN}$ sliding force capacity have been implemented in Shenyang Government Office Buildings in 1997 to retrofit this building, as shown in Figure 7. The pseudodynamic tests of a 1/3 scale model of the building with and without friction dampers were carried out to examine the seismic capacity of the retrofitted buildings [12].

Lead dampers have ideal elastic-plastic property with rectangular hysteresis curve. The yielding limit of lead dampers cannot be adjusted after designed. Hence, in a strong earthquake, the energy dissipation capacity of dampers will be low because of large deformation. Whereas, in a mild earthquake, the dampers cannot yield to dissipate energy. Innovative bend-shear and shear-type lead dampers which can attenuate the vibration of buildings both in mild and strong earthquakes were developed by Zhou et al. [13].

Viscoelastic dampers have the merits of dissipating energy at all deformation levels. Therefore viscoelastic dampers can be applied in both wind and seismic protection. Some commercial products of viscoelastic dampers in China are shown in Figure 8. The mechanical model, design technique, and optimum method for viscoelastic dampers have been developed in China [14,15]. Viscoelastic dampers were also applied to engineering structures for suppressing the structural vibration caused by wind or earthquake in China, such as Suqian Communication Building (Figure 9) and Chaoshan Xinhe Building (Figure 10) $[16,17]$.

Fluids can also be used to dissipate energy; hence many kinds of viscous fluid dampers have been proposed. Commercial viscous fluid dampers with different capacities were 


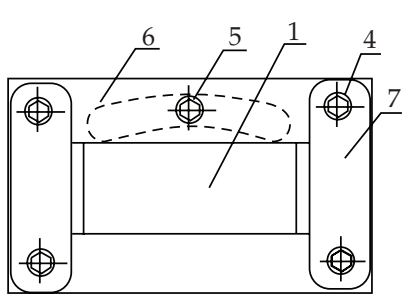

(a) Assembly diagram

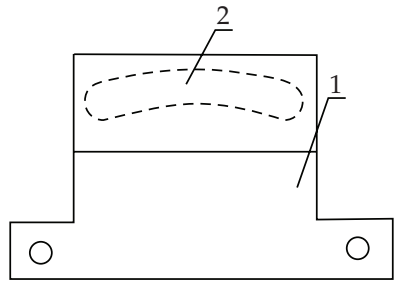

(b) Core plate

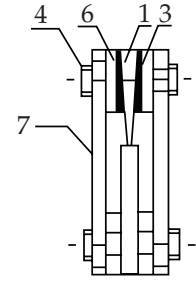

(c) Sectional view

Figure 6: Pseudoviscous frictional damper with convex frictional surface.

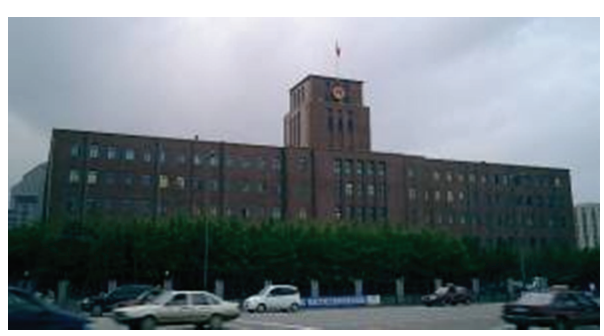

(a)

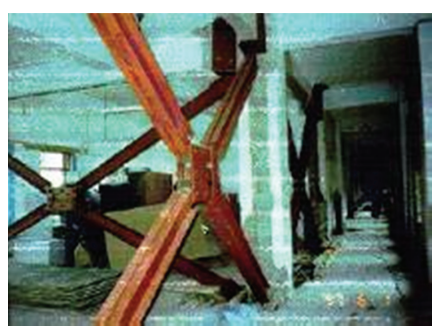

(b)

Figure 7: Shenyang Government Office Building retrofitted by friction dampers.

also available in China (Figure 11). Viscous dampers have been used in some engineering structures in China, including Beijing Yingtai Center, Yizhenyuan building of Huaiyin City, Beijing Exhibition Building, an office building of Suqian City, Construction Building of Suqian City, an office building of Xi'an City, and Beijing Restaurant. The centre tower building of Beijing Yintai Center is a 60-story steel structure with $248 \mathrm{~m}$ in height and susceptible to wind, so 73 sets of viscous fluid dampers were installed in it (Figure 12) [18].

Metallic dampers dissipate energy input to a structure from an earthquake through inelastic deformation of metals. Based on the experimental study and theoretical analysis of the fatigue properties of X-shape steel plate energy dissipaters, the nonlinear method of steel plate of the energy dissipater was established and the strain-fatigue parameters are determined, which provide an important base for the design of mild steel energy dissipaters [19]. In most cases, Metallic dampers dissipate energy through the nonlinear property of steel plate after yielding out of plane. Dual-functional mild steel dampers are presented by G. Li and $\mathrm{H}$. Li [20], as shown in Figures 13 and 14, which is to strengthen the initial stiffness by extending the steel plate in its own plane and to increase the energy-dissipating ability by changing the geometric shape of the steel plate. Results from theoretical analysis and quasistatic experiments showed that these types of mild metallic dampers not only provide certain stiffness in normal use, but also are of good ability of the seismic energy dissipation. Dual-functional mild metallic dampers have been installed in No. 3 Experiment Building of Dalian University of Technology (DUT) in China to increase the stiffness of the first floor and suppress the earthquake induced vibration [21], as shown in Figure 15.

For some old designed buildings based on the dated building design codes in which the seismic protection was seldom taken into account; both the land developers and engineers have to determine whether to demolish them and then set up new ones or reuse the original buildings through making some innovations to meet the current need. Due to economy, many 

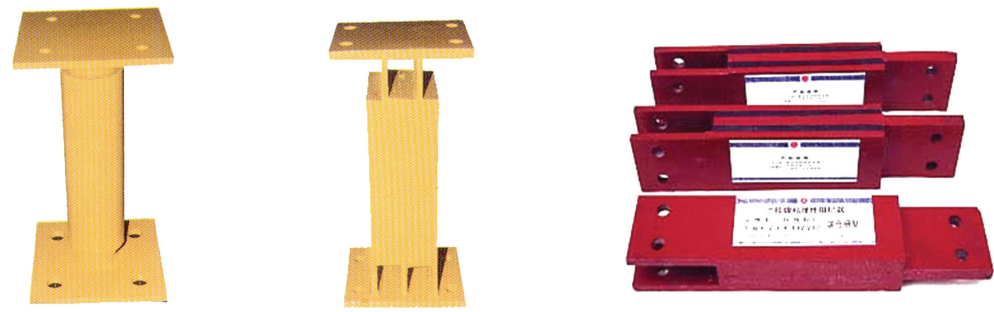

Figure 8: Some commercial products of viscoelastic dampers in China.

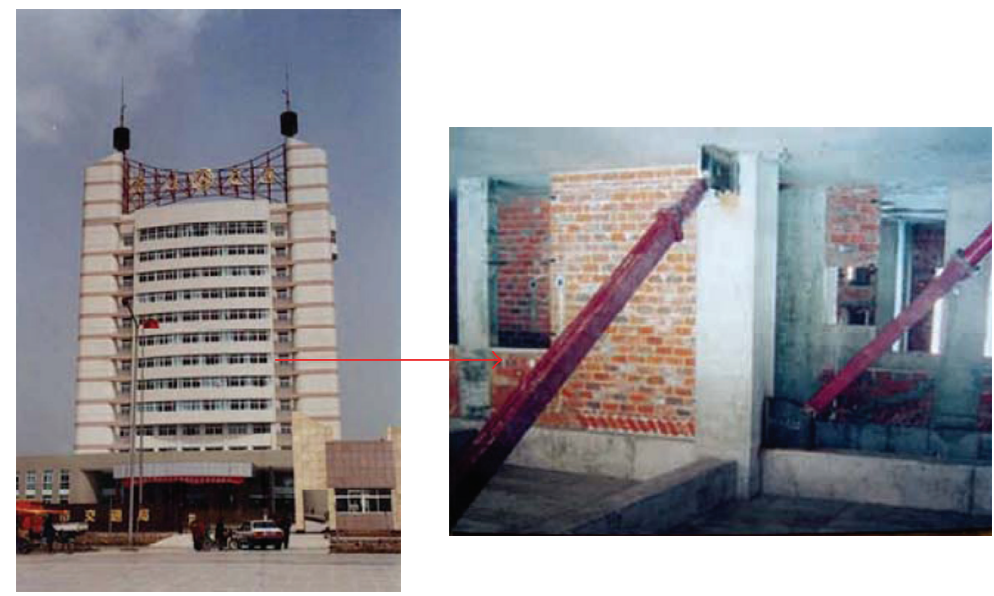

Figure 9: Viscoelastic dampers in Suqian Communication Building.

old existing buildings have been increased with new stories on the top of them in China. A new type of energy-dissipated structural system for the existing building with the storyincreased frame was presented [22], in which the sliding-friction layer between the lowest increased floor of outer frame structure and roof of original building was applied, and energydissipated dampers were used for the connections between the columns of outer frame and each floor of original building, as shown in Figure 16. The experimental results showed that friction and energy-dissipated devices are very effective in reducing the seismic response and dissipating the input energy of model structure. A four-story office building, built up in 1950s without the seismic design along Beiling Street in Shenyang City of China because there was no any seismic codes at that time in China, was designed and analyzed with an increased four-story outer frame structure on its top by using the passive control method presented. The existing building is composed of brick masonry structure; its design is not in compliance with the current Seismic Code of China. The seismic protection intensity on this building site is VII degree, and the site soil belongs to the type II in Chinese Code. The practical building story-increased structure after construction is shown in Figure 17. The results showed that the good seismic-reduction effectiveness on displacements and accelerations can be achieved by installing the friction and energy-dissipated devices in the story-increased structures. 


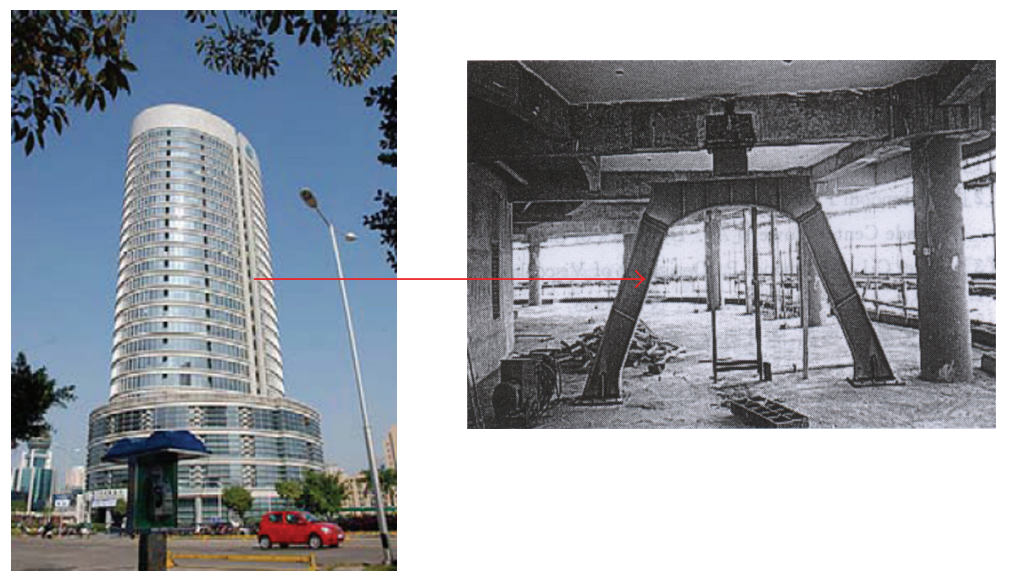

Figure 10: Viscoelastic dampers in Chaoshan Xinhe Building.

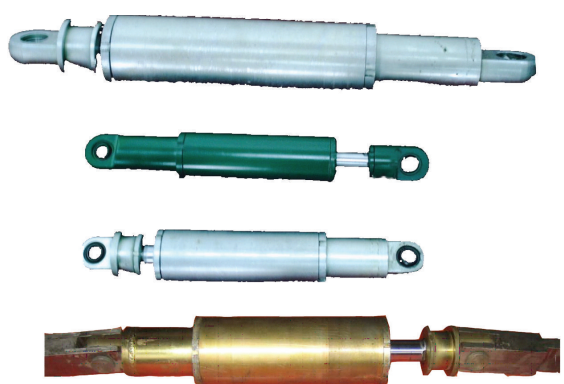

(a)

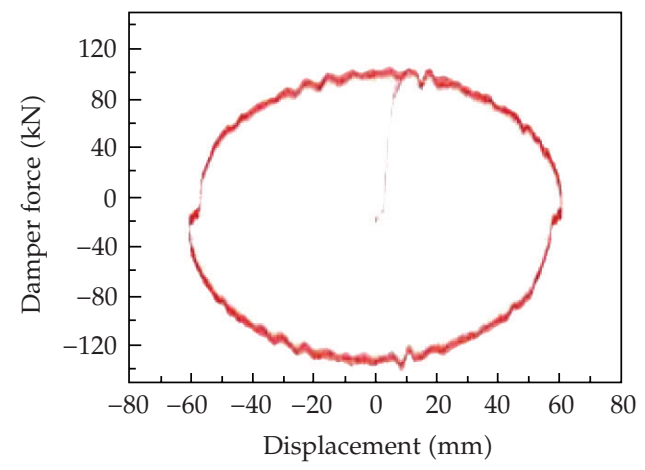

(b)

Figure 11: Some commercial viscous dampers and hysteresis curve.
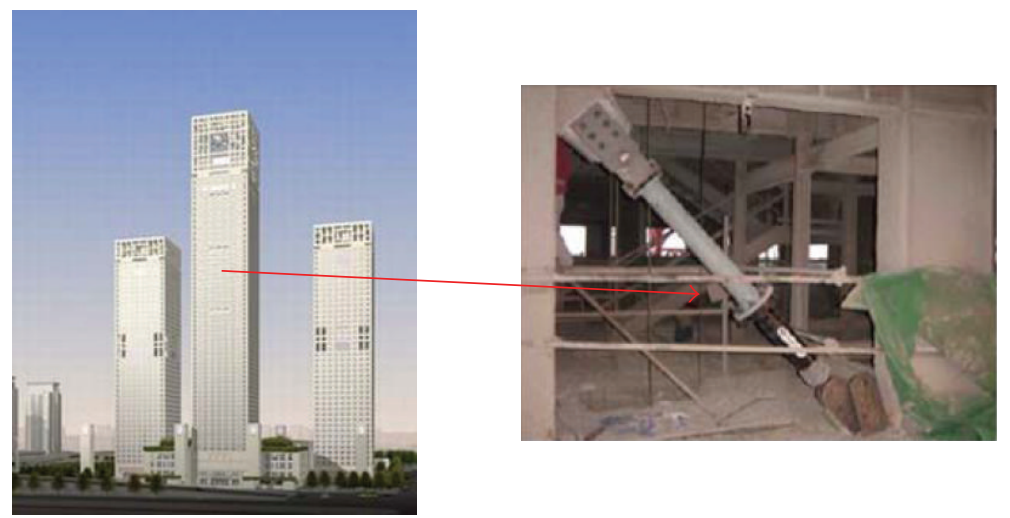

Figure 12: Viscous fluid dampers installed in Beijing Yintai Center. 


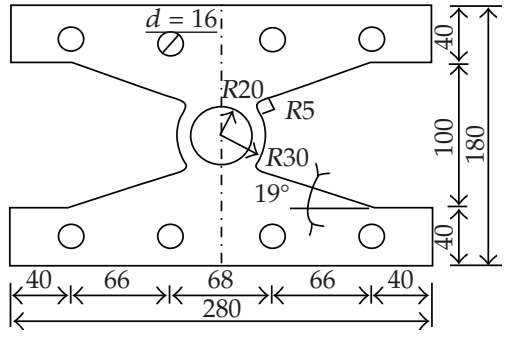

(a)

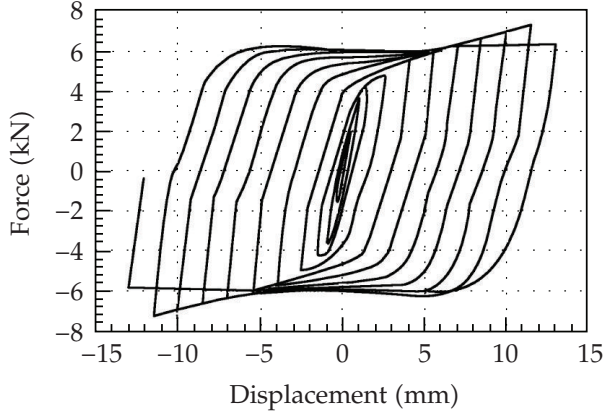

(b)

Figure 13: Circle hole type mild steel damper and its hysteresis curve.

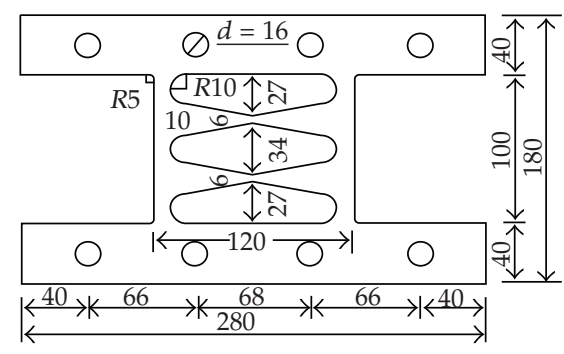

(a)

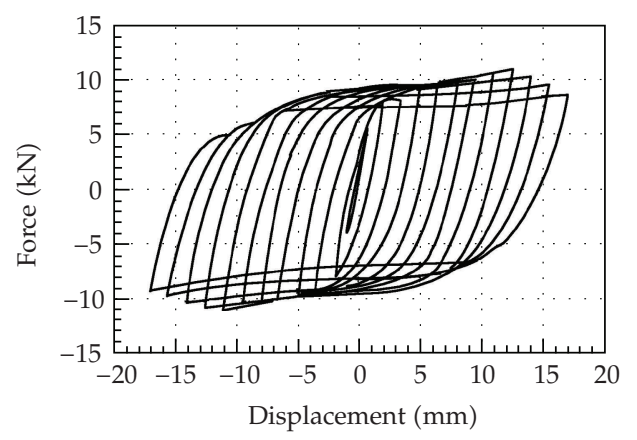

(b)

Figure 14: Double $X$ type mild steel damper and its hysteresis curve.

\subsection{Tuned Mass Damper}

The concept of the tuned mass damper (TMD) consists of a secondary mass with properly tuned spring and damping elements, providing a frequency-dependent hysteresis that increases damping in the primary structure. The frequency of TMD should be tuned to the same as the one of the controlled structures to get the best control results. During an earthquake, TMD will move against the direction of main structural vibration and an inertia force will be acted on the structure to reduce the response of the structure. One TMD can attenuate only the first mode response of a structure with its frequency tuned to the fundamental frequency of the structure. However, the first several modes of a highrise structure are primary and the anticipated response reduction cannot be achieved if only the first mode is controlled. Li and Wang [23] presented the method of using multiple TMDs to control multiple modes of structures and got obvious results of vibration reduction. In China, the TMD system may be formed by adding one or more stories supported by rubber bearings on the roof of main building structure, as shown in Figure 18 [3]. TMD control system was applied in Zhengzhou International Conference and Exhibition Center, as shown in Figure 19. Tuned Mass dampers were also used to suppress the human induced vibration of pedestrian bridges [24-26]. Six sets of TMD system were installed in the box beam of a $52 \mathrm{~m}$-span pedestrian bridge in Shenyang City of China, as shown in Figure 20. 


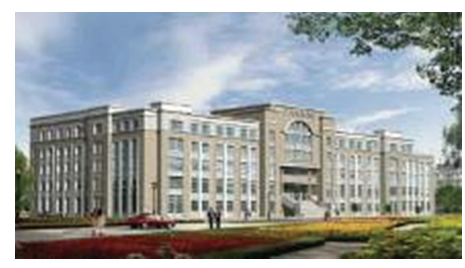

(a)

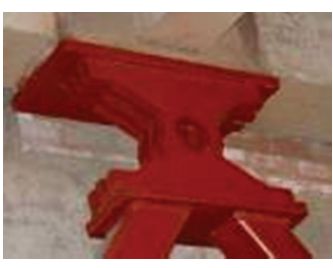

(b)

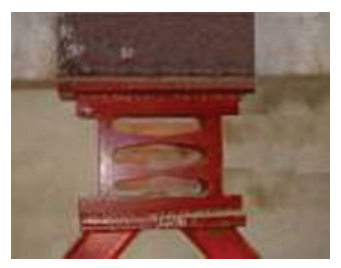

(c)

Figure 15: Double function mild metallic dampers in the No. 3 Experiment Building of DUT.

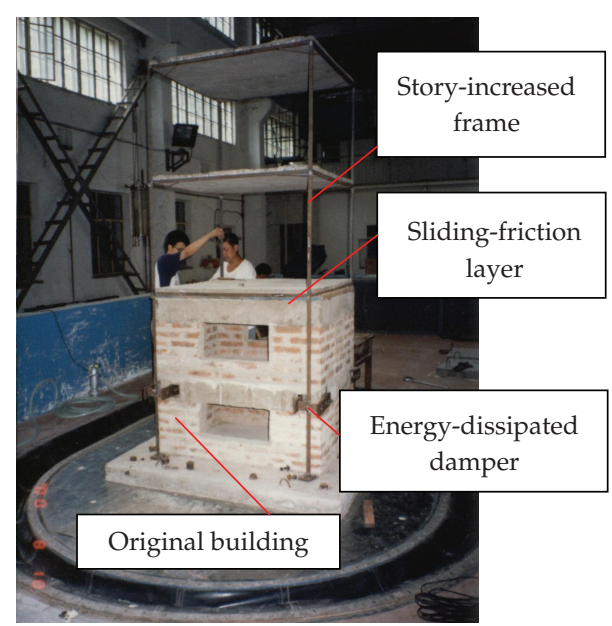

Figure 16: Test model of story-increased system.

\subsection{Tuned Liquid Damper}

Similar in concept a TMD, the tuned liquid damper (TLD) and tuned liquid column damper (TLCD) impart indirect damping to the system and thus improve structural performance. A TLD absorbs structural energy by means of viscous actions of the fluid and wave breaking. In a TLCD, energy is dissipated by the passage of liquid through an orifice with inherent head loss characteristics.

TLDs are mostly used to reduce the wind induced vibration of structures in engineering. Zhang et al. [27] carried out shaking table test and verified the vibration control result with TLD subjected to earthquake. The research shows that TLD is applicable for long period structure. However, it is not enough to consider only the first mode of structural response. Li et al. [28] presented the multimodal vibration control of structures using multiple TLDs and carried out experimental verification. The experimental results showed that reduction effectiveness of the seismic responses for controlling two modes is better than controlling only a single mode.

The frequency of TLCD is related to the length of liquid in the TLCD tube. The length of TLCD maybe too large to exceed the available space of the building for structures with low frequencies. Yan and Li [29] presented the adjustable frequency tuned liquid column damper by adding springs to the TLCD system, which can modify the frequency of TLCD and expended its application ranges (Figure 21). 


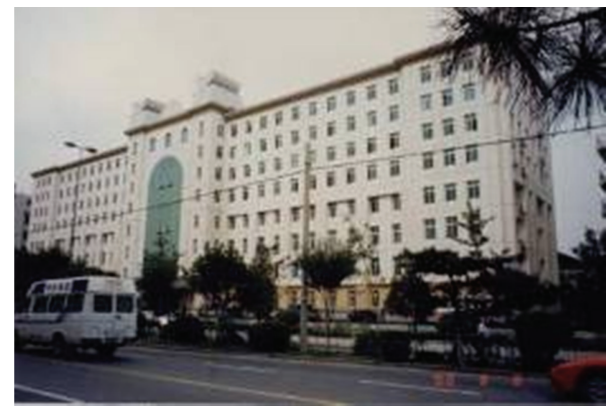

Figure 17: The photo of story-increased building.

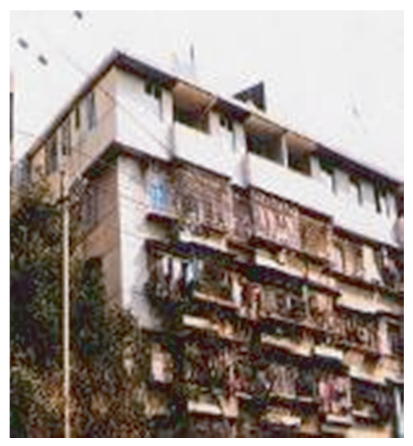

(a)

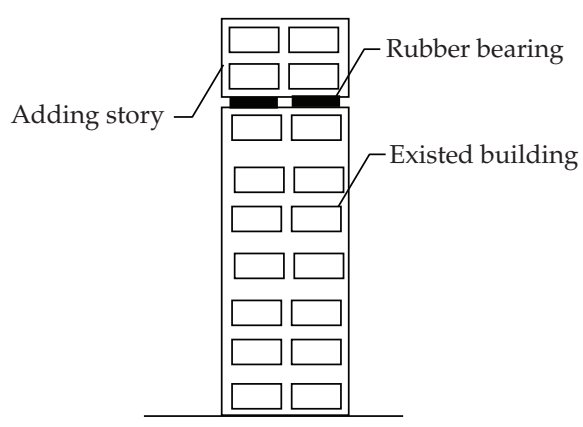

(b)

Figure 18: Adding story of top of building.

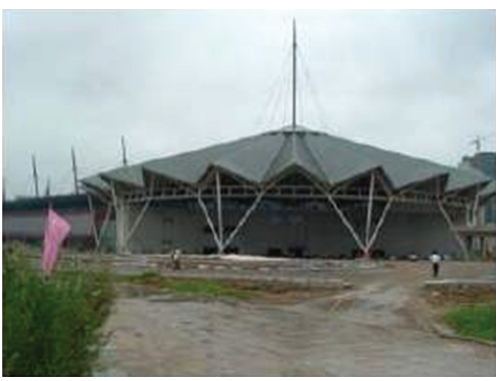

(a)

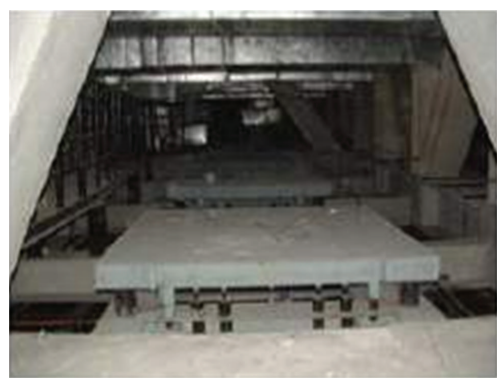

(b)

Figure 19: TMD system in Zhengzhou Conference and Exhibition.
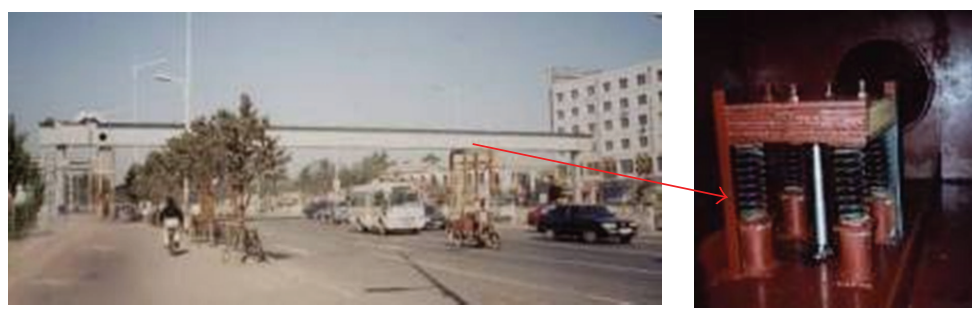

Figure 20: TMD system in a large span pedestrian bridge. 


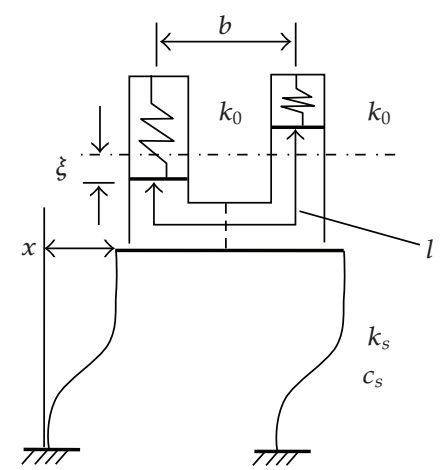

Figure 21: Adjustable frequency TLCD.

To suppress the torsionally coupled responses of structures, Huo and $\mathrm{Li}$ [30] analyzed the control performance of circular tuned liquid damper (CTLCD). Subsequently, TLCD and CTLCD were used to control the torsionally coupled vibration of structures subjected to multidimensional earthquake excitations (Figure 22). The optimal parameters of the liquid dampers are designed for the structures excited by bi-directional seismic based on Genetic Algorithms [31].

Recently, TLD control scheme was proposed to reduce wind-induced vibration of Dalian International Trade Center in China, as shown in Figure 23, which is of 81 stories (including one story basement) with the size of $339 \mathrm{~m}$ high and $77.7 \mathrm{~m}$ long in the east-west direction and $44 \mathrm{~m}$ wide in south-north direction. Since the basic wind pressure in the Dalian region is $0.75 \mathrm{KN} / \mathrm{m}^{2}$ and the mansion is slender, that is, the ratio of height over width is 6.7 , it is relatively more flexible to large wind-vibration action in the horizontal direction. According to numerical results, the designed TLDs in the building can efficiently reduce the structural vibration, and the effects of vibration reduction are going to be better as the increase of liquid mass in tanks, in which the reduction rates may be as high as 19\% for structural acceleration response that influences the human comfort.

\section{Active Control}

Active control systems are used to control the response of structures to internal or external excitation, such as machinery or traffic noise, wind or earthquakes, where the safety or comfort level of the occupants is of concern. Active control may employ hydraulic, pneumatic, electromagnetic, or motor driven ball-screw actuation. The desirable performance of structural systems can be achieved through active control, whereby actuators excite the structure based on the structural response information measured by sensors. Control of structures involves a number of disciplines, including structural dynamics, control theory, and material engineering. The practice of active structural control is still in doubt, therefore, resulting in the slow shift to application from experimental and theoretical study stage.

Active mass damper (AMD) is one of the most common control device employed in full-scale civil engineering. AMD system is designed and installed in the Nanjing Communication Tower in Nanjing, China (Figure 24). The physical size of the damper was constrained to a ring-shaped floor area with inner and outer radius of $3 \mathrm{~m}$ and $6.1 \mathrm{~m}$, respectively. In addition, the damper was elevated off the floor by steel supports with Teflon 


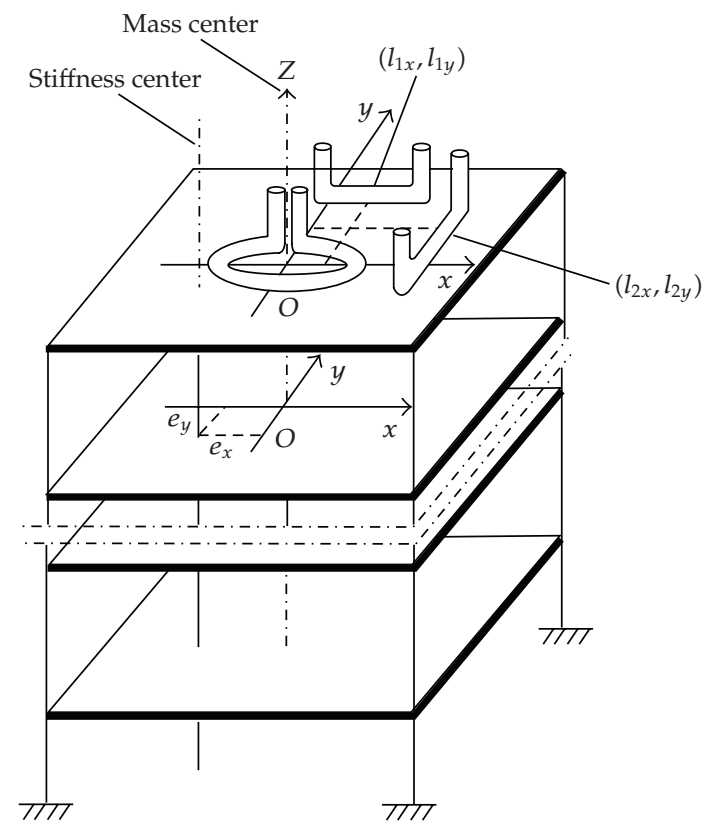

Figure 22: Eccentric structure with liquid dampers.

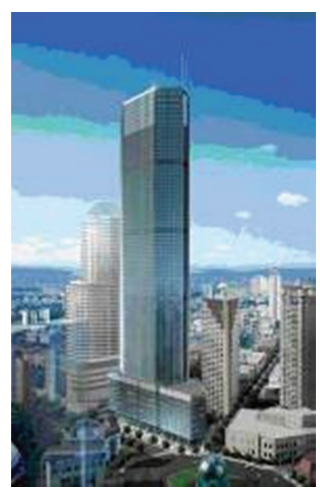

(a)

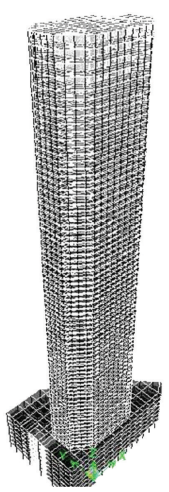

(b)

Figure 23: TLD control scheme for Dalian International Trade Center of China.

bearings to allow free access to the floor area. The final design of the active mass damper is shown in Figure 24 [32]. The AMD control methods for eccentric building structures using artificial network, genetic algorithm, and fuzzy logic were presented by Li and Jin [33] and Jin and Zhou [34].

\section{Hybrid Control and Semiactive Control}

A hybrid control may use active control to supplement and improve the performance of a passive control scheme. Alternatively, passive control may be added to an active control 

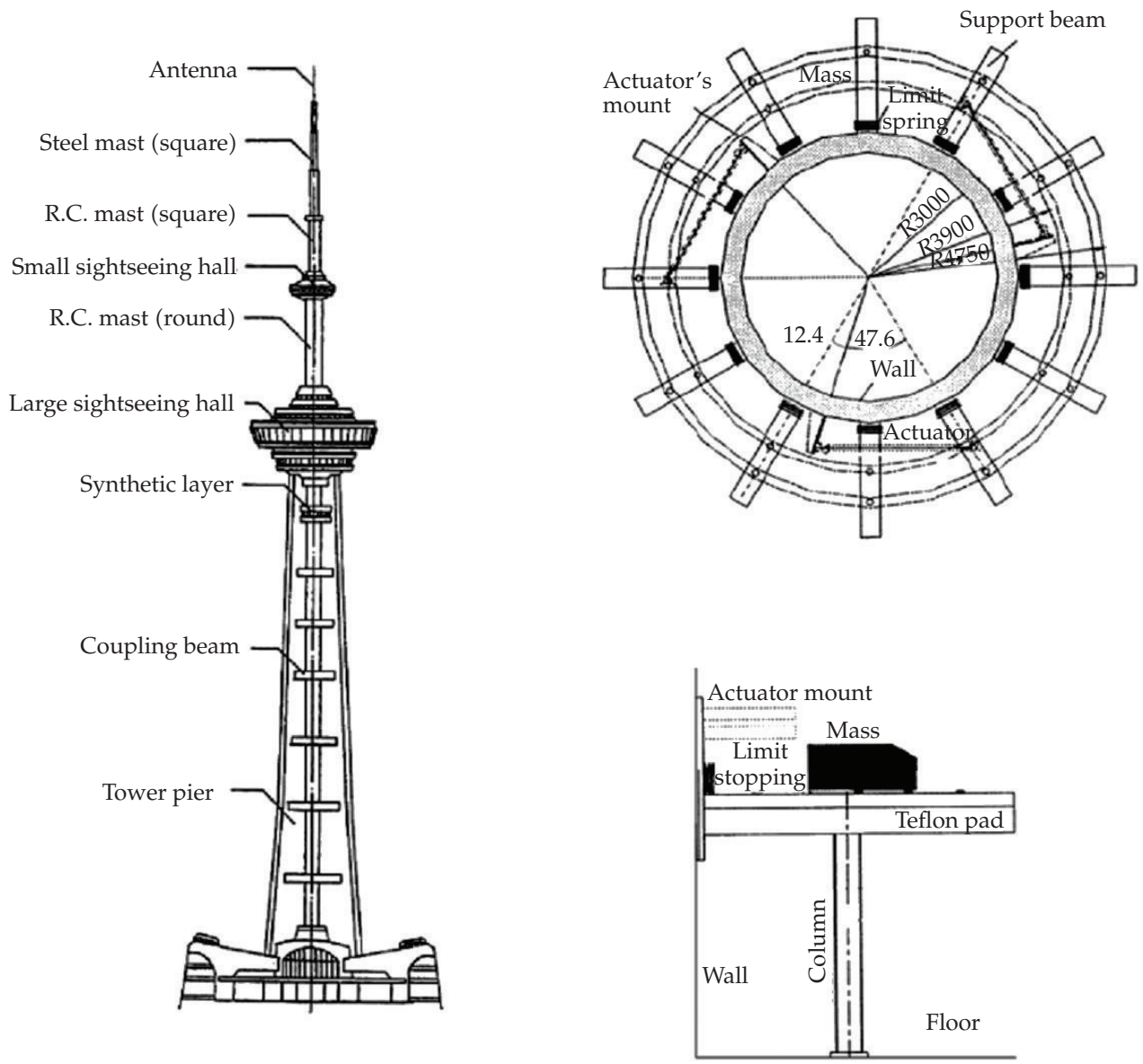

Figure 24: Nanjing Communication Tower with AMD.

scheme to decrease its energy requirements. Hybrid control schemes can sometimes alleviate some of the limitations that exist for either a passive or an active control acting alone, thus leading to an improved solution. One of the hybrid systems is combination of TMD or TLD and active control devices. TMD or TLD is used to control mild responses of structure and active control devices are used to alleviate the large amplitude responses of structures. Hence, the energy required to drive hybrid system is reduced a lot, and the applicability and reliability of the system are increased. According to the characteristics of earthquake response of high-rise buildings with spacious first story, a kind of hybrid control system with hydraulic damper system (HDS) and AMD is proposed. The experimental results of shaking table and simulation analysis indicate that the hybrid control system HDS-AMD has great potentialities for vibration control of civil engineering structures [35]. Guangzhou TV and Sightseeing Tower is a tower currently under construction in Guangzhou City in China, which is total $610 \mathrm{~m}$ high including the $450 \mathrm{~m}$-high main tower and a $160 \mathrm{~m}$-high antenna. The tower is a very flexible structure with the first period about 10.03 and susceptible to wind, hence hybrid TMD control system is proposed for the vibration reduction, in which two water tanks are used as mass block, as shown in Figure 25 [36]. 


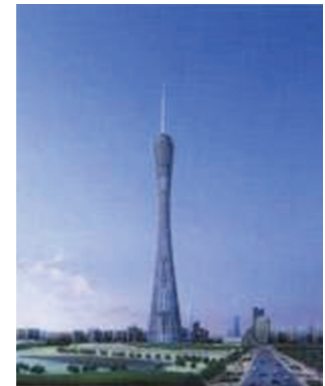

(a)

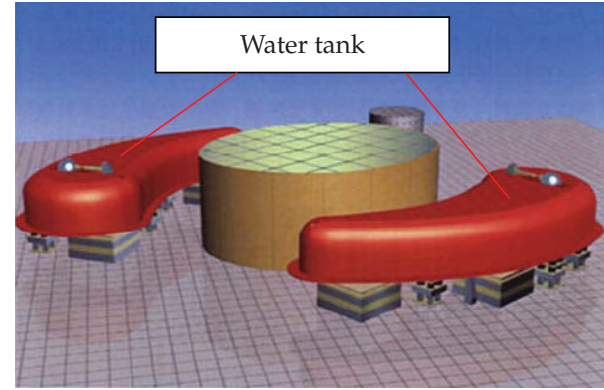

(b)

Figure 25: Hybrid TMD control system for Guangzhou TV Tower.

One of the most attractive features of semi-active control systems is that the external energy required for them to operate is usually orders of magnitude smaller than for active systems. The semi-active control system is much more reliable and simpler than general active control system, and more effective to reduce the structural response than other passive control system. Examples of semi-active control device include variable orifice fluid dampers, variable stiffness devices, semi-active tuned liquid dampers, and controllable friction devices. The behavior of active variable stiffness system is experimentally studied by Li and Liu [37]. Both of the structural analysis and a small-scaled model shaking table test indicated that the variable stiffness system not only changed frequencies of controlled structures but also increased damping ratio. A hydraulic actuator with a controllable orifice was developed by Sun [38]. Li et al. [39] experimentally investigated the electromechanical behavior, which is dependent on exciting frequency and applied voltage. To improve the control performance of passive TLCD, Li et al. proposed the semi-active TLCD control strategy based on Artificial Neural Network (ANN) and fuzzy logic [40,41].

\section{Structural Vibration Control with Smart Materials}

Smart materials refer to materials that are "responsive." Often the response is the conversion of one form of energy into another in useful quantities. Commonly used smart materials in vibration control include Magneto-rheological (MR) fluids, piezoelectric ceramics, and shape memory alloy. Magnetorheological (MR) dampers are one of the most promising devices for structural control of civil engineering structures. MR dampers have the capability to provide large controllable damping forces and to dynamically change their properties to accommodate varying loading conditions and usage patterns. X.-L. Li and H.-N. Li [42] proposed a new MR mechanical model which is called double-sigmoid. The outstanding feature of the proposed model is a fact that magnitude of control current and a wide range of excitation conditions are under consideration. The identification of parameters is relatively easy and the physical concept of the model is obvious through this method. The proposed double-sigmoid MR mechanical model is as follows:

$$
f_{d}=f_{y} \frac{1-e^{-k\left(\dot{x}+\dot{x}_{h}\right)}}{1+e^{-k\left(\dot{x}+\dot{x}_{h}\right)}}+C_{b} \cdot \dot{x}
$$




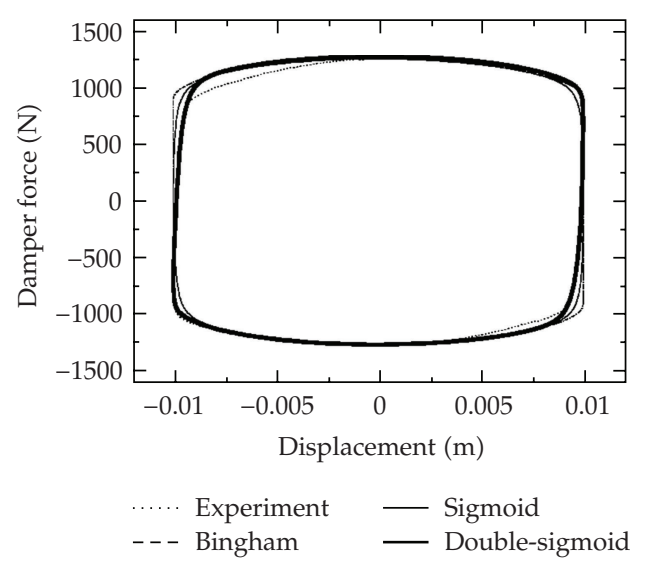

(a)

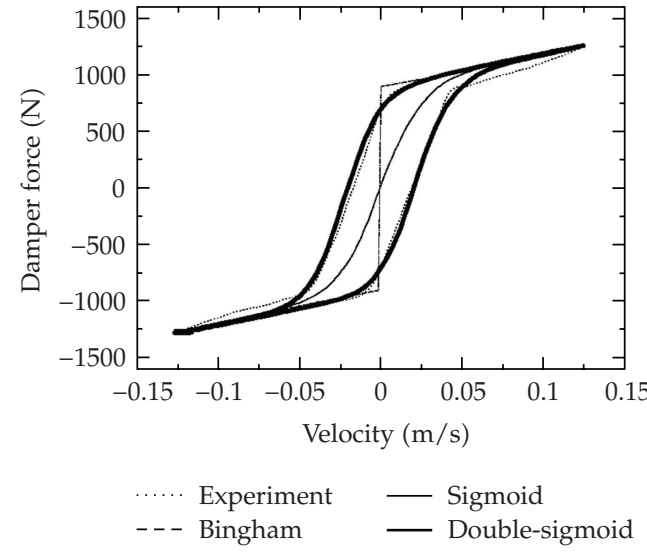

(b)

Figure 26: Force-displacement and force-velocity curves of different models.

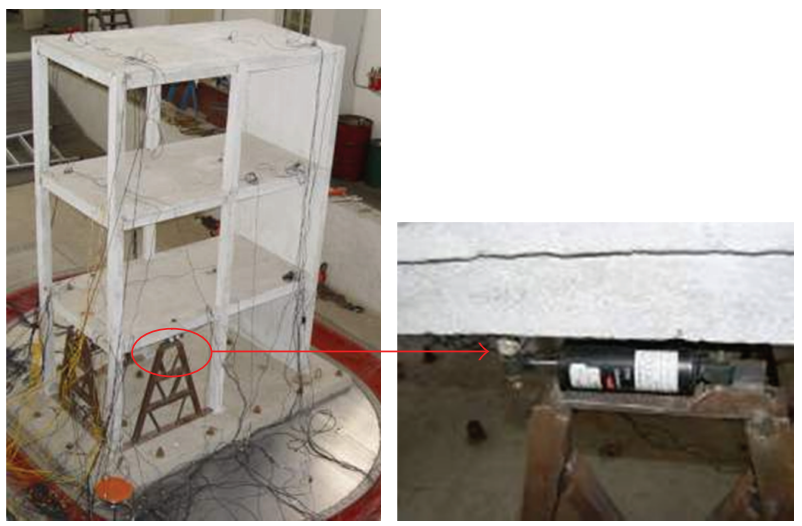

Figure 27: Eccentric vibration control experiment with MR damper.

where $f_{d}$ is the force provided by MR dampers, $f_{y}$ is the yielding force of MR dampers, $k$ is a constant, $\dot{x}$ is the velocity of MR dampers, $C_{b}$ is the damping coefficient of MR dampers, $\dot{x}_{h}$ is traversing velocity of force-velocity curve. To verify the accuracy of proposed MR damper model, force-displacement and force-velocity curves for three different models are computed. Comparison of theoretical and experimental results is shown in Figure 26. It can be seen that the phenomena of the hysteresis nonlinear properties in higher velocity region and the saturation characteristic in lower velocity region of MR dampers can be described accurately using proposed model.

MR damper was proposed to reduce the torsional response of eccentric buildings. The shaking table experiment of a 2-story frame-shear wall structure model with an asymmetric stiffness distribution was carried out, as shown in Figure 27 [43]. The experimental results showed that the coupled translation and torsion response were significantly mitigated.

$256 \mathrm{MR}$ dampers with $2.26 \mathrm{kN}$ capacity at the cables of the Dongting Lake Cable-stayed Bridge of China to suppress the wind-rain induced dramatic vibration, as shown in Figure 28 


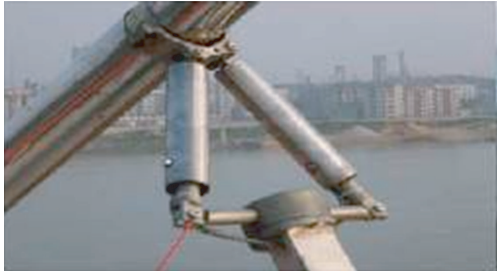

(a)

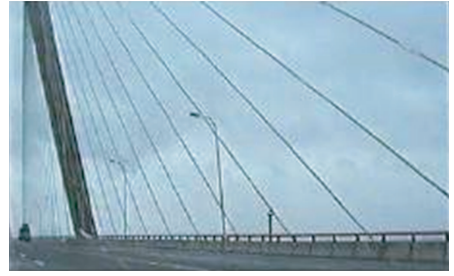

(b)

Figure 28: Dongting Lake Bridge with MR dampers.

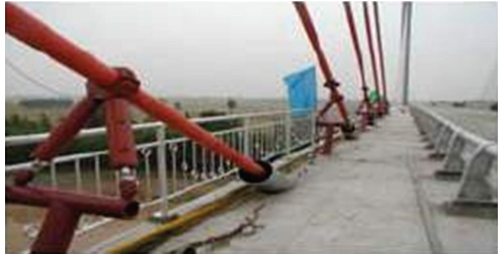

(a)

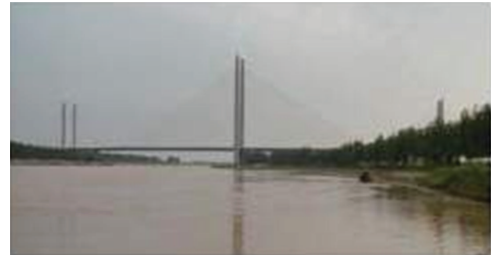

(b)

Figure 29: Binzhou Yellow River Highway Bridge with MR dampers.

[44]. $40 \mathrm{MR}$ dampers with $8 \mathrm{kN}$ capacity at the cables of Shandong Binzhou Yellow River Highway Bridge, as shown in Figure 29 [45].

The variable friction that dampers with a PZT actuator has been proposed by $\mathrm{Ou}$ [45] and other researchers. Although the specific configuration of the damper is different, the mechanism to adjust sliding force is similar, that is, the nominal pressure force can be adjusted through applying voltage to the PZT layer due to its reverse piezoelectric property. A new design for piezoelectric friction damper was presented by Li et al. [46]. This piezoelectric friction damper was developed by combining the existing slot bolted connector design and the piezoceramic actuator. The schematic of this design is shown in Figure 30. It is composed of tube piezoceramic stack actuators, load cells, preload bolts, an upper plate, a sliding plate, and a lower plate. Three plates are slot-bolted together so that sliding takes place among the sliding plate, upper plate, and lower plate. This type of semiactive piezoelectric can be connected to the beams or floors using chevron braces through the connecting plates. A preload is applied to the piezoceramic actuators to avoid slack and constraining the deformation of actuators.

Shape memory alloys (SMAs) are multifunctional materials as they have self-sensing, self-actuating and energy dissipation properties. Many researchers focus on developing SMA-based isolators with self-centering performance. Two kinds of self-sensing, SMA dampers are developed by Li et al. [47]. The self-sensing SMA dampers have following characteristics: (5.1) the SMA wires are always elongated during vibration no matter which direction of the controlled structure move in; (2) the SMA dampers can self-sense deformation, and thus resulting in a potential way to quantificational assess the safety and damage of the controlled structures post-earthquake hazards; (3) one of SMA dampers can dissipate much more energy because the configuration of the SMA damper with amplifying function deform the SMA wires in the damper larger than the corresponding drift of the controlled structure. Ren et al. presented mechanical model of X type SMA damper and 


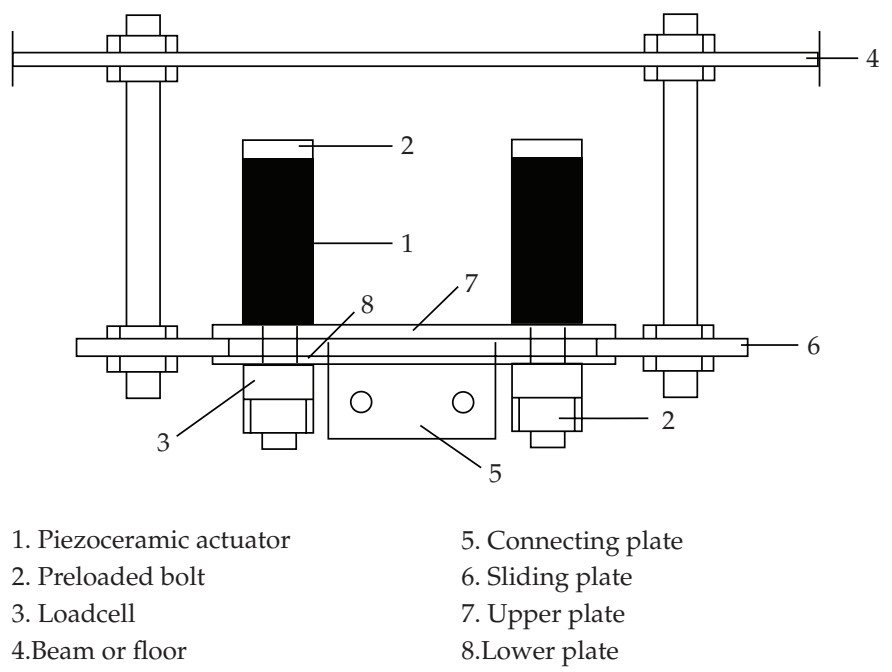

Figure 30: Schematic of a new piezoelectric friction damper.

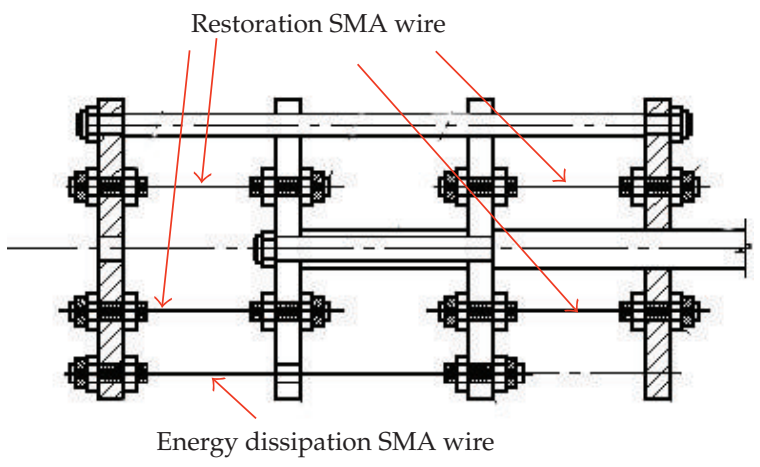

(a)

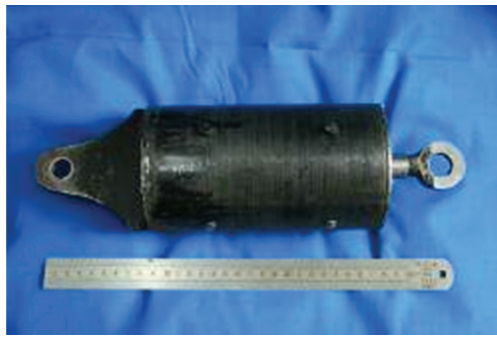

(b)

Figure 31: Energy dissipation and recentering SMA dampers.

a one-dimensional strain-rate dependent constitutive model for SMA [48, 49]. A new type of SMA damper was proposed utilizing the energy dissipating and recentering features of superelastic SMA, as shown in Figure 31 [50]. The research results showed that the innovative SMA damper has both the energy dissipating and recentering features with the hysteretic loop under cyclic loading-unloading. The hysteretic behaviors of the damper can be modified to best fit the needs for passive structural control applications by adjusting the pretension of the Nitinol wires. An innovative multidirectional shape memory alloy damper was developed by Ren et al., as shown in Figure 32 [51], which can dissipate energy on the any direction of horizontal plane and recenter on vertical and torsional direction.

\section{Conclusions}

The researches on structural vibration control have made great achievements, and some control devices have been applied to full-scale engineering structures in the recent years in 


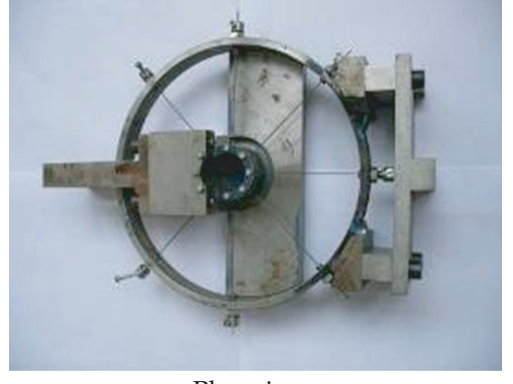

Plan view

(a)

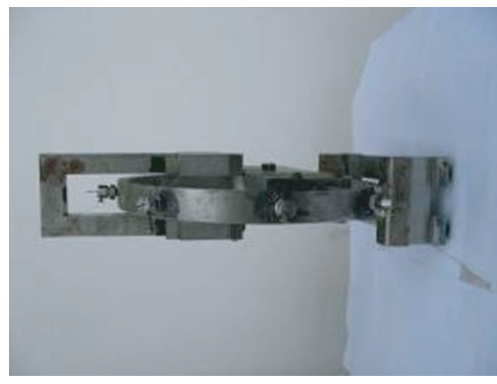

Site view

(b)

Figure 32: Multidimensional SMA damper.

China. However, most researches focus on linear vibration of structures. Studies on control theories for nonlinear systems are still very limited so far and should be paid more attention in the future. Performance-based method for all kinds of control systems should be developed to satisfy the engineering requirements. More smart materials and new technologies should be used to control the structural vibration subjected to dynamic load.

\section{Acknowledgments}

This work was jointly supported by Natural Science Foundation of China (no. 50708016 and 90815026), Special Project of China Earthquake Administration (no. 200808074) and the 111 Project (no. B08014).

\section{References}

[1] F. L. Zhou, Seismic Control of Structures, Chinese Seismic, Beijing, China, 1997.

[2] F. L. Zhou and Q. L. Xian, "Recent development on seismic isolation, energy dissipation, passive and semi-active control of structures in P. R. China," in Proceedings of the China-U.S. Millennium Symposium on Earthquake Engineering: Earthquake Engineering Frontiers in the New Millennium, Beijing, China, November 2000.

[3] F. L. Zhou, P. Tan, Q. L. Xian, X. Y. Huang, and Z. Yang, "Research and application of seismic isolation system for building structures," Journal of Architecture and Civil Engineering, vol. 12, no. 2, pp. 1-8, 2006.

[4] H.-N. Li and X.-X. Wu, "Limitations of height-to-width ratio for base-isolated buildings under earthquake," Structural Design of Tall and Special Buildings, vol. 15, no. 3, pp. 277-287, 2006 (Chinese).

[5] H. N. Li and X. X. Wu, "Simplified formulate of torsional seismic actions for base-isolated eccentric structures," Journal of the Harbin Institute of Technology, vol. 26, no. 1, pp. 52-54, 2004 (Chinese).

[6] J. P. Ou, "Some recent advances of structural vibration control in mainland China," in Proceedings of the 3rd International Conference on Earthquake Engineering, Nanjing, China, October 2004.

[7] Y. Zhou and J. Liu, "Comparative experimental study on the behavior of two different energy dissipation brace based on friction," Earthquake Engineering and Engineering Vibration, vol. 17, no. 1, p. 48, 1997 (Chinese).

[8] W. Y. Zhang and W. B. Yang, "Experimental investigation on the braced frame with double phase friction attenuation controller under low frequency cyclic loading," Building Science, vol. 13, no. 4, pp. 3-7, 1997 (Chinese).

[9] B. Wu and J. P. Ou, "Behavior of pseudo-viscous friction energy dissipators," World Information on Earthquake Engineering, vol. 15, no. 11, pp. 1-11, 1999 (Chinese). 
[10] B. Wu, J.-G. Zhang, and J.-P. Ou, "Numerical analysis of hysteretic behavior and brace force of pseudoviscous frictional dampers," Journal of Harbin Institute of Technology, vol. 35, no. 7, pp. 834-843, 2003 (Chinese).

[11] Q. L. Xian, F. L. Zhou, C. M. Zhang, and G. H. Yu, “Design and test and analysis of the mix friction energy dissipation bracings used for high-rise buildings," World Information on Earthquake Engineering, vol. 12, no. 1, pp. 1-9, 1996 (Chinese).

[12] B. Wu, H. Li, and L. Y. Lin, "Retrofitting of Shenyang Government Office Building by friction dampers," Journal of Architecture and Buildings, vol. 19, no. 5, pp. 28-36, 1998 (Chinese).

[13] Y. Zhou, F. L. Zhou, and X.-S. Deng, "Research on lead damper and its applications," World Information on Earthquake Engineering, vol. 15, no. 1, pp. 53-61, 1999 (Chinese).

[14] Z. Xu, Z. Zhou, H. Zhao, and Y. Shen, "A new method on viscoelastic dampers," Engineering Mechanics, vol. 18, no. 6, pp. 88-92, 2001 (Chinese).

[15] Q. Zhang, W. Lou, and Y. Chen, "Parameter design and location optimum practical method of viscoelastic dampers," Structural Engineers, vol. 19, no. 3, pp. 39-44, 2003 (Chinese).

[16] W. Cheng, J. Sui, Y. Chen, et al., "Design and earthquake absorption using viscoelastic damper in transportation building of Suqian city," Journal of Building Structures, vol. 21, no. 3, pp. 30-35, 2000 (Chinese).

[17] Y. Yin, Y. Zhou, and L. B. Mei, "Transient dynamic finite element analysis about energy dissipation structure of Chaoshan-xinghe building," Earthquake Resistant Engineering and Retrofitting, vol. 27, no. 3, pp. 35-40, 2005 (Chinese).

[18] G. P. Zhao, Y. Lu, P. B. Li, H. J. Han, Z. C. Lu, and J. Huang, “Using viscous dampers to control windinduced vibration for steel tower of Beijing Yintai Center," Building Structures, vol. 37, no. 11, pp. 8-10, 2007 (Chinese).

[19] B. Wu and J. P. Ou, "Fatigue properties and design criteria of mild steel yielding energy dissipaters," World Information on Earthquake Engineering, vol. 12, no. 4, pp. 8-13, 1996 (Chinese).

[20] G. Li and H. Li, "Study on vibration reduction of structure with a new type of mild metallic dampers," Journal of Vibration and Shock, vol. 25, no. 3, pp. 66-72, 2006 (Chinese).

[21] H.-N. Li and G. Li, "Experimental study of structure with "dual function" metallic dampers," Engineering Structures, vol. 29, no. 8, pp. 1917-1928, 2007.

[22] H.-N. Li, Y.-W. Yin, and S.-Y. Wang, "Studies on seismic reduction of story-increased buildings with friction layer and energy-dissipated devices," Earthquake Engineering and Structural Dynamics, vol. 32, no. 14, pp. 2143-2160, 2003.

[23] H. N. Li and S. Y. Wang, "Seismic vibration control of high-rise buildings using TMD," Journal of Engineering Mechanics, vol. 14, no. A03, pp. 136-140, 1997 (Chinese).

[24] Z. Q. Ye, A. Q. Li, and Y. L. Ding, “The vibration energy dissipation design of a pedestrian bridge (1)," Special Structures, vol. 20, no. 1, pp. 68-70, 2003 (Chinese).

[25] Y. L. Ding, A. Q. Li, and Z. Q. Ye, "The vibration energy dissipation design of a pedestrian bridge (2)," Special Structures, vol. 20, no. 1, pp. 71-73, 2003 (Chinese).

[26] L. S. Huo and H. N. Li, "Theoretical analysis of vibration control of large-span pedestrian bridge by use of MTMD," Journal of Disaster Prevention and Mitigation Engineering, vol. 28, no. 3, pp. 298-302, 2008 (Chinese).

[27] M. Z. Zhang, S. W. Ding, and X. Guo, "Study on structure control using tuned sloshing damper," Earthquake Engineering E Engineering Vibration, vol. 13, no. 1, pp. 40-48, 1993 (Chinese).

[28] H. Li, L. Zhang, and Y. S. Yang, "A study on vibration reduction in high-rise structures by multiTLDs," Earthquake Engineering and Engineering Vibration, vol. 17, no. 1, p. 23, 1997 (Chinese).

[29] S. Yan and H. N. Li, "Vibration control parameters research on system with adjustable frequency tuned liquid column damper," Earthquake Engineering and Engineering Vibration, vol. 18, no. 4, pp. 96-101, 1998 (Chinese).

[30] L.-S. Huo and H.-N. Li, "Torsion-coupled response control of structures using circular tuned liquid column dampers," Journal of Engineering Mechanics, vol. 22, no. 2, pp. 124-131, 2005 (Chinese).

[31] H.-N. Li and L.-S. Huo, "Optimal design of liquid dampers for structural torsion coupled vibration," Chinese Journal of Computational Mechanics, vol. 22, no. 2, pp. 129-134, 2005 (Chinese).

[32] B. F. Spencer and T. T. Song, "New applications and development of active, semi-active and hybrid control techniques for seismic and non-seismic vibration in the USA," in Proceedings of the International Post-SMiRT Seminar on Seismic Isolation, Passive Energy Dissipation and Active Control of Vibration of Structures, Cheju, Korea, 1999.

[33] H.-N. Li and Q. Jin, "AMD active control for irregular buildings using GA-BP neural network," Earthquake Engineering and Engineering Vibration, vol. 23, no. 2, pp. 134-142, 2003 (Chinese). 
[34] Q. Jin and J. Zhou, "Discrete-time variable structure control method for AMD-eccentric buildings with time delay in control," Journal of Harbin Institute of Technology, vol. 37, no. 6, pp. 790-794, 2005 (Chinese).

[35] A. Qi, J. Liu, and H. Li, "Hybrid control research on earthquake responses of high-rise building with spacious first story," Journal of Vibration Engineering, vol. 12, no. 2, pp. 256-261, 1999 (Chinese).

[36] J. Teng, Z.-X. Lu, Y.-Q. Xiao, A.-Z. Yan, and C.-T. Li, "Vibration control of high-rising buildings with TMD considering contact non-linear damping effect," Journal of Vibration and Shock, vol. 28, no. 3, pp. 90-97, 2009 (Chinese).

[37] M. X. Li and J. Liu, "Semi-active control for structural vibration using variable stiffness with nonlinear damping," Journal of Vibration Engineering, vol. 11, no. 3, pp. 333-339, 1998 (Chinese).

[38] Z. Y. Sun, Experimental study on variable orifice dampers, Ph.D. dissertation, Harbin Institute of Technology, Harbin, China, 1998.

[39] H. Li, X. S. Yuan, and B. Wu, "Variable orifice dampers: experiments and analysis," Journal of Vibration Engineering, vol. 15, no. 1, pp. 15-30, 2002.

[40] H.-N. Li, L.-S. Huo, and S. Yan, "TLCD semi-active control for irregular buildings using neural networks," Earthquake Engineering and Engineering Vibration, vol. 21, no. 4, pp. 135-141, 2001 (Chinese).

[41] H. Li and Q. Jin, "TLCD semi-active control for irregular buildings using fuzzy neural network based on Takagi-Sugeno model," Chinese Journal of Computational Mechanics, vol. 20, no. 5, pp. 523-529, 2003 (Chinese).

[42] X.-L. Li and H.-N. Li, "Double-sigmoid model for magnetorheological damper and corresponding experiment verification," Journal of Vibration Engineering, vol. 19, no. 2, pp. 168-172, 2006 (Chinese).

[43] X.-L. Li and H.-N. Li, "Experimental study of semi-active control of coupled translation and torsion response for frame-shear wall eccentric structure," Journal of Dalian University of Technology, vol. 48, no. 5, pp. 691-697, 2008 (Chinese).

[44] J. M. Ko, Y. Q. Ni, Z. Q. Chen, and B. F. Spencer, "Implementation of MR dampers to Dongting Lake Bridge for cable vibration mitigation," in Proceeding of the 3rd World Conference on Structural Control, Como, Italy, 2002.

[45] J. P. Ou, Structural Vibration Control-Active, Semi-Active and Smart Control Systems, Press of Science, Beijing, China, 2003.

[46] J. Li, H. N. Li, and G. Song, "Semi-active vibration suppression using piezoelectric friction dampers based on sub-optimal bang-bang control laws," in Proceedings of the 3rd China-Japan-US Symposium on Structural Health Monitoring and Control, Dalian, China, 2004.

[47] H. Li, C. X. Mao, and J. P. Ou, "Shape memory alloy-based smart building," in Proceedings of the 8th US National Conference on Earthquake Engineering, San Francisco, Calif, USA, 2006.

[48] W. Ren, H. Li, and G. Song, "Mechanical model of X type SMA plate damper," Journal of Vibration and Shock, vol. 25, no. 4, pp. 53-57, 2006 (Chinese).

[49] W. Ren, H. Li, and G. Song, "A one-dimensional strain-rate-dependent constitutive model for superelastic shape memory alloys," Smart Materials and Structures, vol. 16, no. 1, pp. 191-197, 2007.

[50] H.-N. Li, H. Qian, G.-B. Song, and D.-W. Gao, "Type of shape memory alloy damper: design, experiment and numerical simulation," Journal of Vibration Engineering, vol. 21, no. 2, pp. 179-184, 2008.

[51] W. Ren, H. Li, and G. Song, "Design and numerical evaluation of an innovative multi-directional shape memory alloy damper," in Active and Passive Smart Structures and Integrated Systems 2007, vol. 6525 of Proceedings of SPIE, San Diego, Calif, USA, March 2007. 


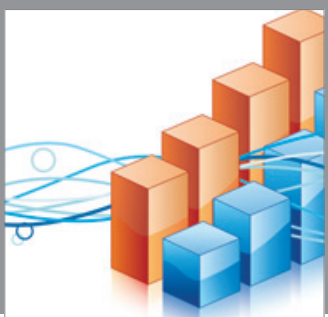

Advances in

Operations Research

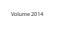

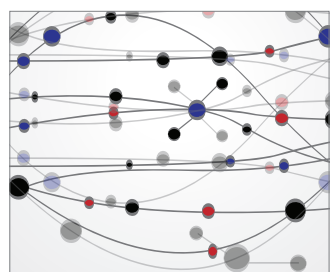

\section{The Scientific} World Journal
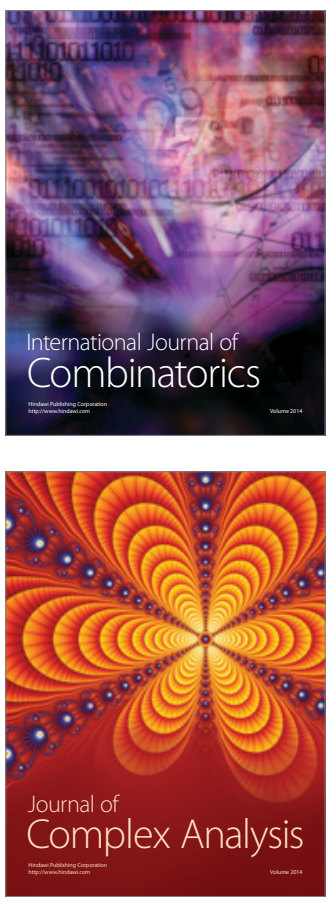

International Journal of

Mathematics and

Mathematical

Sciences
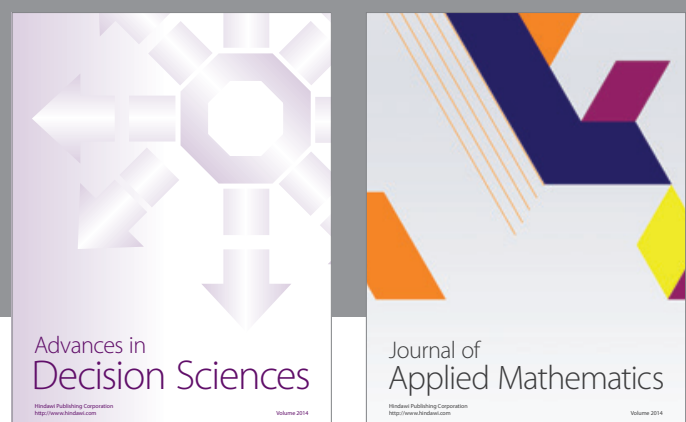

Journal of

Applied Mathematics
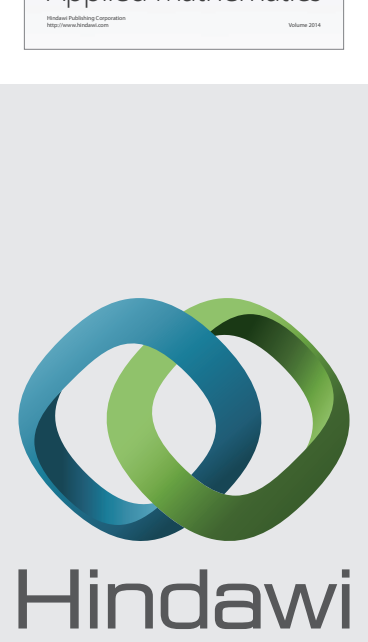

Submit your manuscripts at http://www.hindawi.com
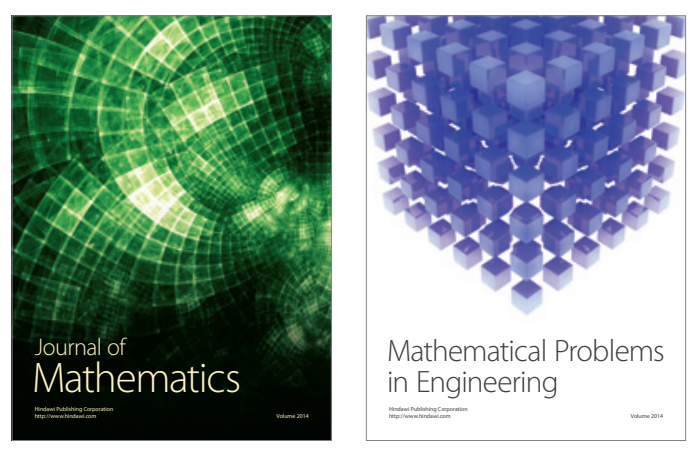

Mathematical Problems in Engineering
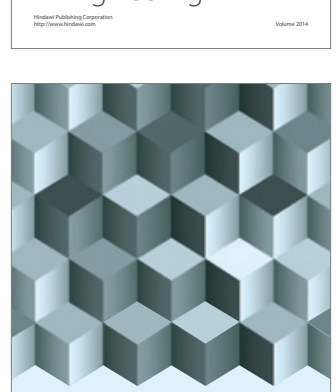

Journal of

Function Spaces
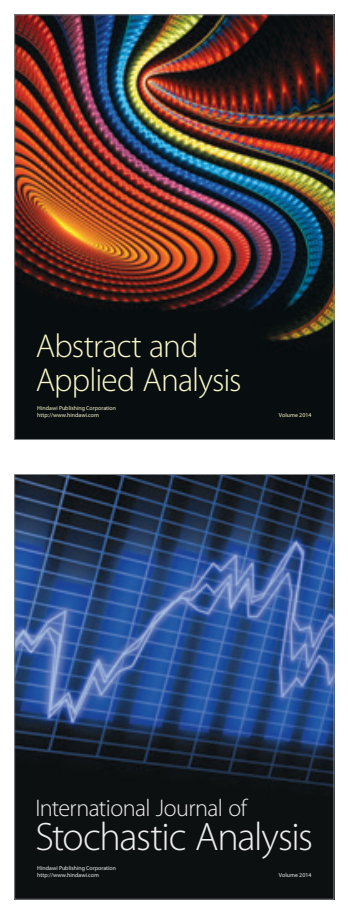

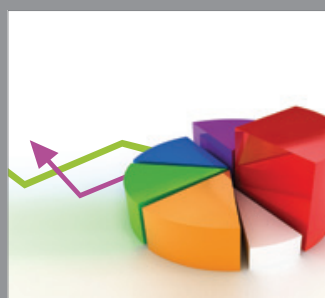

ournal of

Probability and Statistics

Promensencen
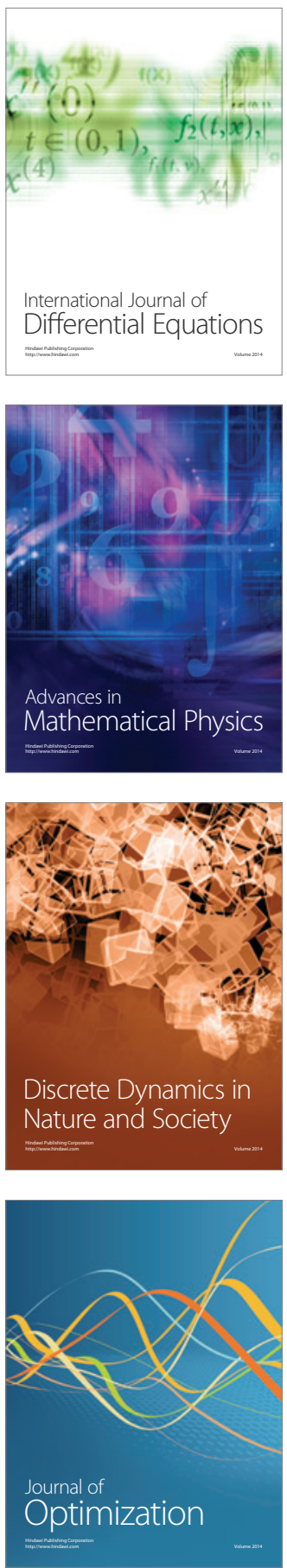